\title{
INVESTIGACIÓN/RESEARCH
}

\section{LOS PAISAJES DEL SUEÑO AMERICANO: ESCENOGRAFÍA DE 'MAD MEN'}

Francisco Cabezuelo Lorenzo: Universidad de Valladolid, Segovia, España. cabezuelo@hmca.uva.es

Cristina González Oñate: Universitat Jaume I, Castellón, España. onate@com.uji.es

Carlos Fanjul Peyró: Universitat Jaume I, Castellón, España. fanjul@com.uji.es

\section{RESUMEN}

Este artículo analiza el reflejo del sueño americano en los escenarios, iconología y modelos de belleza usados por Matt Weiner en su exitosa serie Mad Men (AMC, 2007). Esta serie de se ha convertido en obra de ficción audiovisual mundialmente aclamada y premiada repetidamente en todo el mundo, sobre todo por su autenticidad histórica y su estilo visual. La serie se convierte en un perfecto retrato de un mundo gris de hombres ejecutivos, en el que la única nota de color la ponen las mujeres. Se trata de una mujer bella, elegante, guapa, moderna, coqueta, femenina que tiene ante sí el nuevo reto de ocupar puestos de responsabilidad en el mundo laboral y al mismo tiempo de llevar una familia hacia delante como ama de casa y esposa. Paradójicamente, ese realismo y verosimilitud despiertan el interés por una realidad intangible y tan difícil de concretar como es el sueño americano.

PALABRAS CLAVE: Mad Men - Escenografía - Series de televisión - Norteamérica

\footnotetext{
${ }^{1}$ Francisco Cabezuelo Lorenzo: Facultad de Ciencias Sociales, Jurídicas y de la Comunicación de la Universidad de Valladolid. Campus de Segovia. España.
}

Correo: cabezuelo@hmca.uva.es 


\section{THE AMERICAN DREAM LANDSCAPES: SET DESING AND STAGING OF 'MAD MEN'}

\section{ABSTRACT}

This article analyses the reflex of the American dream in the sets, iconology and beauty models used by Matt Weiner in his successful TV series drama Mad Men (AMC, 2007-Hoy). This TV drama has turned into an audio-visual fiction master piece that the world has acclaimed and internationally rewarded in the whole world, especially for his historical genuineness and his visual style. It turns into a perfect portrait of a grey world of executive men, where the women put the only and unique note of colour. These women are beautiful, elegant, handsome, modern, flirtatious and feminine and have the new challenge of occupying positions of responsibility in the labour world. Paradoxically, this realism and verisimilitude wake the interest up for a reality intangible and so difficult to make concrete since it is the American dream.

KEYWORDS: Mad Men - Set design - TV Drama Series - North America

\section{INTRODUCCIÓN}

\subsection{El embrujo de la estética y los escenarios del pasado.}

La exitosa serie de televisión norteamericana Mad Men (Mad Men, Matthew Weiner, AMC, 2007-2013) se ha convertido en obra de ficción audiovisual mundialmente aclamada y premiada en todo el mundo, sobre todo por su autenticidad histórica y su estilo visual. La serie se centra en la vida del ejecutivo publicitario Donald Draper, rol interpretado por el actor Jon Hamm.

Esta ficción audiovisual cuenta no solo la vida de este alto ejecutivo del mundo de la publicidad y las relaciones públicas, sino que también retrata con mucho acierto a todo el colectivo profesional representado por Draper, (Ferré, 2011: 56-57) es decir, a toda la gente del gremio con la que el protagonista trata en lo profesional y lo personal tanto dentro como fuera de su oficina en la ficticia agencia 'Sterling Cooper Draper Price' en la céntrica Madison Avenue, en el distrito de Manhattan (en Nueva York, Estados Unidos), epicentro de las grandes agencias de publicidad internacionales en los años sesenta en la cuna del capitalismo en plena Guerra Fría.

El propio título de la serie, Mad Men, es una anfibología. Al mismo tiempo significa "hombres locos" y a la vez hace referencia a los "hombres de la calle Madison", que eran los ejecutivos más envidiados de la pujante sociedad de consumo americana que resurge con fuerza tras la II Guerra Mundial y va en aumento durante los primeros años del enfrentamiento entre los dos grandes modelos (capitalismo y comunismo), en esos años cincuenta y sesenta en los que se consolida un modelo social, moral y familiar típicamente norteamericano, por contraposición a modelos sociales y políticos del momento (Mendelsohn, 2011: 46). 
Para muchos críticos, la excelente visión que la serie ideada por Matthew Weiner, ex guionista de The Sopranos, se ha convertido en una acertada mirada a los hombres y mujeres que dieron origen y forma al moderno sueño americano, a la época dorada de la cultura contemporánea norteamericana (Brox, 2009). Otro de los grandes motivos por los que esta ficción audiovisual ha sido aplaudida por crítica y público, además de su misterioso guión, ha sido por su reconstrucción de ambientes.

A través de una excelente reconstrucción de escenarios, vestuarios y detalles, junto con un brillante guión, la serie muestra los cambios sociales, estéticos y morales que sufrió la sociedad norteamericana desde 1962. Por tanto, este estudio supone una mirada desde el año 2013, por un lado, al trabajo desarrollado por los creadores de la serie, puesta en marcha en 2007, y al mismo tiempo, paralelamente, a los Estados Unidos de los años sesenta, una época dorada multitud de veces reflejada por la industria cultural norteamericana.

\section{METODOLOGÍA}

\subsection{Fundamentos para el análisis: La deconstrucción del sueño americano.}

Del mismo modo este artículo, que forma parte un proyecto de análisis e investigación más amplio, se asienta sobre fundamentos interdisciplinares diversos asentados por otros autores (Ferreras, 1999; González Requena, 2010; Gubern, 2006; Requeijo, 2010; Talens \& Zunzunegui, 2007). Parte de los Estudios Culturales y la Comunicación Audiovisual, pero se adentra a su vez en la Sociología y la Historia, todo ello para dar una visión más completa del objeto de estudio.

El objetivo principal de esta comunicación es descubrir las estrategias, tácticas y herramientas para la reconstrucción de los escenarios, ambientes, contextos y lugares propios de los años sesenta y ver cómo se integran en ellos algunos modelos de belleza usados en la serie de televisión norteamericana Mad Men para lograr la reconstrucción de los modelos estéticos de la época y dotarla de credibilidad. Del mismo modo, este trabajo pretende demostrar que la serie cumple con el rigor científico e histórico necesario para lograr la tan valorada verosimilitud, en la que la reconstrucción de escenarios y ambientes es un pilar fundamental. Sus fuentes documentales son adecuadas y redundan en la calidad del producto final.

Con vistas a demostrar la anterior hipótesis y alcanzar los objetivos, se hace un análisis de contenidos de los trece capítulos que conforman la primera temporada de Mad Men. Se hace un estudio pormenorizado de vestuario, complementos, peluquería, maquillaje y aspectos físicos de los personajes. Éstas y otras variables se miden de forman cuantitativa y se intercalan con análisis y valoraciones cualitativas. Metodológicamente, este artículo analiza no solo los trece episodios de la primera temporada, sino que también revisa documentación complementaria como 'Componiendo Mad Men' (Composing Mad Men, AMC, 2007) sobre la música creada para la serie por David Carbonara. Igualmente, se somete a análisis el documental titulado Publicidad, el sueño americano (Advertising, the American Dream, AMC, 2007) y los tres reportajes que componen el making-off de la serie. 


\section{3.- ANÁLISIS Y DISCUSIÓN}

\subsection{La plasmación estética del sueño americano en sus días de oro.}

A la hora de analizar la reconstrucción de la estética típicamente americana es preciso hacer una reflexión sobre el pensamiento, sociedad, moral y estética de la Norteamérica de los años cincuenta y sesenta, haciendo hincapié en tres cuestiones: el sueño americano, que simboliza el esplendor de América, la fuerza y renacer con fuerza de la publicidad, y el incipiente rol y peso social de la mujer en la sociedad del momento (Cabezuelo Lorenzo, 2011).

El concepto y término sueño americano ha evolucionado y cambiando en la historia reciente de EEUU, pero a lo largo de estos años ha mantenido un significado. Evoca multitud de ejemplos y realidades, siempre ligado al afán de superación y al deseo de un vida mejor en un país como Estados Unidos, que ha acogido desde sus orígenes a gentes de diferentes razas, culturas y orígenes y los ha integrado bajo una misma bandera, convirtiéndose en un líder económico y en uno de los sistemas democráticos más estables del mundo.

En verdad, se podría afirmar que el sueño americano viene a definirse como la igualdad de oportunidades y la libertad que permite que todos los ciudadanos estadounidenses sean capaces, gracias a la igualdad de oportunidades, el esfuerzo y la perseverancia de lograr aquello que se propongan en la vida.

Hoy en día, la idea del sueño americano hace referencia a la prosperidad de los americanos, fruto de su trabajo, no en un sentido rígido de jerarquía social. Para muchos, es la oportunidad de lograr un futuro mejor y un bienestar para ellos y sus hijos, del que no disfrutaban en su infancia o del que no gozaron sus antepasados (Díez, 2011: 156).

El sueño americano es para muchos un mito, un ficción, es algo realmente onírico y ficticio. En el caso de la ficción, en Mad Men, su protagonista, Donald Draper, refleja también el sueño americano (Rubio Alcover, 2011: 12). Un niño de una familia pobre y rural con graves desgracias personales termina convirtiéndose en un ejecutivo de mucho éxito en el campo de la publicidad en Nueva York.

\subsection{La recreación estética: deconstrucción y reconstrucción de la realidad histórica.}

Según Scott Hornbacher, productor de la serie, «dar verosimilitud era una de las cosas más importantes para todos, porque algo más es vergonzoso, es poco profesional y puede resultar poco creíble a la gente». Se pretende reconstruir la belleza del momento, no desde la fantasía y el mundo de los sueños y tópicos. Es más bonito un Cadillac, pero la reconstrucción exacta exige que el coche del protagonista sea otro. Es el coche que tenemos en nuestra memoria, pero es un producto idealizado. No había tantos coches como esos en la América de esos años. La realidad era otra. 
Sirva para explicar esta deconstrucción y reconstrucción con una anécdota. Un asistente de producción cuanta como el creador de la serie le riñó una vez por poner un escenario que simulaba una frutería con una variedad de manzanas grandes y rojas. Pues bien, Matt Weiner, creador de la serie, riñó a su asistente. Según Weiner en los años sesenta todavía no existían esas manzanas tan perfectas y brillantes que conocemos hoy. Son fruto de experimentos agrícolas y comerciales posteriores. Pidió que se retiraran del decorado esas manzanas actuales.

Respecto al diseño del decorado se tiene cuidado con todo lo que atañe y rodea a los actores, los accesorios, todo lo que tocan. La autenticidad es lo primero de la serie. «Todos los que trabajamos en este tema tenemos imágenes en la cabeza que junto con el creador de la serie intentan expresarnos constantemente qué detalles usar para que no vayamos en una dirección inadecuada para la época», según la decoradora Amy Wells.

Según Scott Buckwald, colaborador de Weiner, este trabajo «va más allá de las cosas que tocan los actores», según afirma en el making-off. «En muchas ocasiones hay que prestar especial atención a los detalles. Es lo que hacemos nosotros. Cuando empezamos la serie, llenamos metros y metros de mesas de cigarros, puros, radio transistores, cámaras, cualquier cosa que pudieras encontrar en las casas de la época o que esperases encontrar en los 60», recuerda el experto en escenografía.

«En cierto momento, Matt nos pidió que pusiéramos un muñeco para que los niños jugaran en la parte trasera del coche. Cuando hice mi búsqueda y aunque la serie tiene lugar en abril de 1960, ese juguete salió a la venta en verano de ese año. Matt quería ser fiel a la época así que quitamos ese trozo. Esto nos permite mantenernos fieles a la época y el ambiente que trabajamos. Mantener la verosimilitud histórica permite desarrollar los personajes como Matt los ideó. $Y$ hace que trabajemos todos en sintonía. En el episodio en el que se veía el primer episodio en spray. Así que mediante fotos y artículos de revistas antiguos, recreamos la marca. En la escena, cuando se lo echan a la cara, no podía ser desodorante, así que es una botella de mentira que lleva agua dentro», según Scott Buckwald.

Estos detalles se trabajan en todo momento. Otro ejemplo que encontramos en la serie es el caso de la tarta de la marca 'Sarah Lee' que aparece en un frigorífico. Los expertos y profesionales de la materia, tuvieron que reproducir el viejo logo de la famosa marca americana de dulces. El logo había evolucionado con el paso de los años y el actual no valía. No era el mismo.

De acuerdo con Robin Veith, asistente de los guionistas, varias obras han servido para inspirar Mad Men y reconstruir esos modelos de belleza americana de la época. Documentalmente, se ha hecho mucho uso de revistas de aquellos años como New Yorkers y obras como The Family Mystique, Sex and single girls, Sex and the office también de los años sesenta. 


\subsection{La recreación de espacios: escenarios reales y construcciones efímeras.}

Para Matt Roush, crítico de televisión de la revista TV Guide Critic, la serie es «realmente un producto evocador en muchos aspectos, pero lo que de verdad te retrotrae al Manhattan del pasado, al Manhattan donde todo era brillante y nuevo es la limpieza de la oficina y que no hay saturación todavía». Hay muchos contrastes con las diferentes caras de Nueva York que se muestran en la serie. «Ya sólo en términos de producción, la manera en que han mezclado bohemia con suburbio hace que te intereses por la vida de Don Draper», afirma este crítico en el making-off de la serie. Sin embargo, hay que decir, que a pesar de estas buenas críticas a la hora de mostrar cómo era Nueva York en los años cincuenta y sesenta, la serie está grabada en la ciudad de Los Ángeles (California).

Se grabaron solo algunos totales en Nueva York para el episodio piloto, pero la serie se trasladó a la Costa Oeste. Hay algunos escenarios reales y otros inventados. Destacan las propias oficinas de la ficticia agencia 'Sterling Coopers Draper Price' de Nueva York, que en verdad corresponden a la décima planta de una vieja torre de despachos en Los Ángeles, la casa de Donald Draper, que en verdad es una casa en California, algunos bares y restaurantes que conservan el estilo de la época y un apartamento neoyorkino, el piso de Midge, la amante bohemia del protagonista.

Este piso es una de las localizaciones que se grabaron al principio. Don va a casa de Midge, llama a la puerta y entra en el Edificio Bendorm de la calle 57 en la planta 44, en Nueva York. Parece un loft, aunque en aquella época todavía no existía ese tipo de pisos ni el concepto, aunque sí muchos artistas que vivían en estudios. Aunque era espectacular, en verdad el edificio apenas tenía tres ascensores y todos del tamaño de una cabina de teléfonos, por lo que se hacía casi imposible el rodaje allí. Al final se decidió construir un 'set' en Los Ángeles, que está influenciado por lo que fue en el episodio piloto de Nueva York. La habitación está inspirada en un estudio de artista en alguna parte del Midtown de Maniatan. Entre los escenarios reales se han usado restaurantes como The Windsor, The Winter y el Hotel Ambassador.

Una de las escenas que más bellas de la serie tiene lugar en el episodio trece, cuando Betty Draper va al banco caminando bajo la nieve. En verdad, este capítulo fue rodado en el sur de Pasadena a $40^{\circ} \mathrm{C}$. El equipo de rodaje encontró un edificio muy típico de la arquitectura de esa época y que mantenía el entorno y requisitos físicos de la época. Simularon la nieve. Se puso nieve artificial en primer plano, coches de época y hacerlo más creíble, y fue un éxito, quedó muy realista. Parece que Betty está en verdad en un pueblecito durante el invierno.

La casa de los Draper también está en verdad en la localidad californiana de Pasadena, pero en la ficción nos lo ofrecen como si fuera Connecticut, en la Costa Este. Y lo hace bastante bien. Sabiendo que habría exteriores e interiores, en las escenas y que queríamos que miraran por las ventanas para dar más sentido, usamos el exterior como base de la planta del interior de la casa. Si controlábamos eso, controlábamos la posición de escenas y actores», afirma el creador de la serie M. Weiner en el making off. 


\subsection{Escenarios masculinos para mujeres que cambiaron la historia.}

La serie muestra el origen de los actuales roles sociales de la mujer en las sociedades occidentales de hoy en día. Refleja la incorporación de la mujer al mundo del trabajo en las categorías más medias y altas de la empresa (Cabezuelo Lorenzo, 2010). En un primer momento, la mujer se había incorporado a la industria en cadenas de montaje o grandes talleres de costura. La serie muestra la incorporación de la mujer en tareas superiores como la gestión de la empresa y la dirección de comunicación (Sánchez Renieblas, 2011: 33).

Es el caso de dos personajes de la serie. Uno es Joan Holloway, directora de las secretarias de toda la agencia, y el otro es el Peggy Olson, que pasa de ser secretaria a ser una ejecutiva creativa de la agencia (French, 2011). Igualmente, también se ofrece el rol de una nueva mujer que quiere sentirse realizada como ama de casa y esposa, pero que sigue las tendencias y la actualidad. Este rol es el interpretado por la actriz January Jones, en el papel de Betty.

Desde un punto de vista puramente estético, la serie 'Mad Men' establece paralelismos con tres modelos de mujer reproducidos en la serie y que sirven de inspiración para los modelos estéticos como con Jackie Kennedy, Tippi Hendren y Betty Friedan.

En el caso de la viuda del presidente de los Estados Unidos, como primera dama, uno de los primeros proyectos de la mujer de John F. Kennedy fue redecorar la casa presidencial. El Día de San Valentín de 1962, fecha en la que se retoma la segunda temporada de la serie, Jackie hizo un recorrido televisado mostrando la nueva imagen de la Casa Blanca, antes las cámaras de televisión, que eran el nuevo gran medio de comunicación. Con esas imágenes de Jackie y el reportaje sobre la nueva decoración de la Casa Blanca empieza la segunda temporada. Frente a sus anteriores inquilinos, el matrimonio presidencial Eisenhower que de mucha mayor edad que los Kennedy, la pareja demócrata reflejaba juventud e ilusión, éxito y esperanza, reflejaban también el sueño americano.

«Los Kennedy eran perfectos para aquella época. Finalizaba la era Eisenhower y los Kennedy eran glamorosos y jóvenes. Se les veía fantásticos», afirma Arlene Manos en el making-off. De este modo, Jackie Kennedy se convierte también en un modelo de belleza que ha marcado un antes y un después y que ha dado la vuelta al mundo. Su vestuario, especialmente faldas y vestidos, inspirará a personajes como Betty o Joan (García, 2010: 42).

La serie también utiliza como modelo a la bella actriz norteamericana Tippi Hendren, protagonista del film Los pájaros (The Birds, Alfred Hitchcock, 1963). Hendren, muy conocida también por ser la madre de la también actriz Melanie Griffith, supone estéticamente un claro ejemplo de belleza estadounidense de la época. En los sesenta, Tippi Hendren marcó la imagen de las mujeres de principios de los sesenta. En la serie muchas actrices aparecerían vestidas, maquilladas y peinadas como ella. Es el caso de Betty Draper. 
Igualmente, otro modelo de mujer recala en la serie. Los modelos de belleza no responden solo a aspectos físicos y externos. Hay también detrás de ellos un planteamiento filosófico o ideológico. Esta lectura hace que puedan ser propuestos en la serie de forma indirecta otros prototipos de mujer y otras concepciones de la belleza.

La tercera mujer con influencia en la serie es la teórica y líder del movimiento feminista estadounidense, Betty Friedan, que en 1963 publicó el libro La mística de la feminidad con el que asentaba en Estados Unidos las bases del movimiento feminista (Hammer, 2010). De este modo, tenemos a la mujer bella que piensa y trabaja y defiende sus ideas, una mujer con valores.

Otro de los aspectos que han tenido que ser cuidados de forma extrema ha sido el uso de complementos y detalles, (Guarnaccia, 2009) tanto en cuestión de vestuario como de elementos de atrezzo y decorado (Gimeno Alonso, 2010).

\section{CONCLUSIONES}

\subsection{Una buena ambientación histórica es sólo fruto de la investigación.}

Sin duda alguna, la verosimilitud, fruto de la investigación y documentación, se convierte en el factor que da realismo y credibilidad a las series de ficción basadas en otras épocas aumentando su rigor, calidad e interés. Paradójicamente, ese realismo y verosimilitud despiertan el interés por una realidad intangible y tan difícil de concretar como es el sueño americano.

Sólo la adecuada investigación y la correcta documentación se manifiestan como actividades válidas para la configuración exacta o más aproximada posible a la recuperación de escenarios y ambientaciones históricas reales, en este caso, aquellas que sirven para reproducir la estética norteamericana de los años sesenta y sus cánones estéticos, tal y como se reflejan en la serie, lo que ha hecho que Mad Men sea valedora de numerosos premios y muy buenas críticas, hasta convertirla en una serie de culto por los amantes del cine y las series de ficción de calidad.

Al mismo tiempo, la serie se convierte en un perfecto retrato de un mundo gris de hombres ejecutivos, en el que la única nota de color la ponen las mujeres. Se trata de una mujer bella, elegante, guapa, moderna, coqueta, femenina que tiene ante sí el nuevo reto de ocupar puestos de responsabilidad en el mundo laboral y al mismo tiempo de llevar una familia hacia delante como ama de casa y esposa. Son los diferentes roles desarrollados por personajes como Joan, Peggy o Betty.

Los creadores de la serie usan figuras reales como Jackie Kennedy, Tippi Hendren o las escritoras Betty Friedan y Helen Gurly Brown. La serie rinde homenaje inconscientemente a títulos con los que tiene mucho en común en el fondo y en la forma con Mad Men, como es el caso de algunas películas que son clásicos americanos de los años 50 y 60 como Pijama para dos (Lover Come Back, Delbert Mann, 1961) o El hombre del traje gris (The Man in the Grey Frannel Suit, Nunnally Johnson, 1954). 
La reconstrucción de la estética de los años dorados del sueño americano se fundamenta en el trabajo en profundidad en cuestiones ligadas al estudio del maquillaje, el vestuario, y sobre todo en escenarios reales y ficticios, propios de los años sesenta, que generan especialmente gracias a los decorados y la ambientación musical un contexto real y creíble para contar buenas historias.

\section{BIBLIOGRAFÍA}

Brox, S. (2009). Mad Men. L'Atalante: revista de estudios cinematográficos, ISSN 1885-3730, №. 8, 2009, págs. 20-25.

Cabezuelo Lorenzo, F. (2010). La imagen del 'sueño americano: estética y modelos de belleza de la sociedad americana a través de Mad Men. Icono14, ISSN-e 1697-8293, Vol. 8, NN$^{\circ} .3$.

Cabezuelo Lorenzo, F. (2011). Mad Men: where the truth lies. Previously on: estudios interdisciplinarios sobre la ficción televisiva en la Tercera Edad de Oro de la Televisión. Coord. por Miguel Ángel Pérez Gómez, ISBN 978-84-695-1808-3, págs. 685-699.

Ferreras, J. I. (1999): Por(contra) la (pos)modernidad. Madrid. Editorial Endymion.

Díez, D. Épicas modernas: El Estilo Internacional de Mad Men. Teatro marítimo, ISSN 2174-6435, No. 1, 2011, págs. 156-177.

Ferré, J. F. (2011). Ciudadano Draper (fragmentos) sobre "Mad Men". Quimera: Revista de literatura, ISSN 0211-3325, No 332, 2011, págs. 56-57.

French, S. (2011). You gotta let them know what kind of guy you are, then they'll know what kind of girl to be: Gendered Identity and Fantasy in Mad Men. Previously on: estudios interdisciplinarios sobre la ficción televisiva en la Tercera Edad de Oro de la Televisión. Coord. por Miguel Ángel Pérez Gómez. Págs. 549-566.

García, M. (2010). Estilo Mad Men. Cinemanía, ISSN 1135-5840, №. 181. Págs. 42-45.

Gimeno Alonso, S. (2010): Mad Men y el arte de la exactitud, en VV. AA: Guía de Mad Men. Reyes de la Avenida Madison. Editorial Capitán Swing. Madrid.

González Requena, J. (2010): Crónicas del vacío, en VV. AA: Guía de Mad Men. Reyes de la Avenida Madison. Editorial Capitán Swing. Madrid.

Guarnaccia, F. (2009). Cose. Il potere degli oggetti in Mad Men. Comunicazioni sociali, Vol. 31, №. 1. Págs. 48-57.

Gubern, R. (2006). Historia del Cine. Barcelona. Lumen. 
Hammer, E. (2010). El hombre del traje de franela gris: el nuevo conformismo, la ropa de caballero y las políticas de consenso, en VV. AA: Guía de Mad Men. Reyes de la Avenida Madison. Editorial Capitán Swing. Madrid.

Mendelsohn, D. El compte de Mad Men. L' Avenç: Revista de història i cultura. № 367. Págs. 46-55.

Requeijo Rey, P. (2010). Mad Men desde el Análisis Transaccional: las claves de sus protagonistas. Revista de análisis transaccional y psicología humanista. №. 63. Págs. 261-279.

Rubio Alcover, A. (2011). Carbon-copy de los años cuerdos: a propósito de Mad Men. L'Atalante: revista de estudios cinematográficos, ISSN 1885-3730, №. 11, 2011, págs. 12-18.

Sánchez Renieblas, S. (2012). Women at home and women in the workplace in Matthew Weiner's Mad Men. Investigaciones feministas: papeles de estudios de mujeres, feministas y de género. №. 3. Págs. 33-42.

Talens, J. \& Zunzunegui, S. [Eds] (2007). Contracampo: ensayos sobre Teoría e Historia del Cine. Madrid. Cátedra.

VV. AA. (2010). Mad Men: Reyes de la Avda. Madison. Prólogo de Concepción Cascajosa Virino, Jesús González Requena. Madrid. Capitán Swing Libros.

\section{Francisco Cabezuelo Lorenzo}

Profesor ayudante doctor del área de Comunicación Audiovisual y Publicidad de la Facultad de Ciencias Sociales, Jurídicas y de la Comunicación de la Universidad de Valladolid (Campus de Segovia). Cuenta varios postgrados y estancias internacionales. Es autor de más de 30 artículos en revistas indexadas españolas e internacionales de reconocido prestigio, 50 colaboraciones en obras colectivas y coordinado varias obras.

\section{Cristina González Oñate}

Profesora contratada doctora en el Departamento de Ciencias de la Comunicación de la Universitat Jaume I de Castellón. Es licenciada en Publicidad y Relaciones Públicas y en Comunicación Audiovisual, por esta misma universidad, por la que también es doctora. Es autora de más de una docena de artículos en revistas científicas de reconocido prestigio. Las últimas tendencias en televisión forman parte de una de sus principales líneas de investigación.

\section{Carlos Fanjul Peyró}

Profesor contratado doctor en el Departamento de Ciencias de la Comunicación de la Universidad Jaume I de Castellón, por la que también es doctor. Es licenciado en 
Publicidad y Relaciones Públicas por la Universidad Cardenal Herrera CEU de Valencia. Es autor de más de una docena de artículos científicos. 